\title{
A New Approach of Sperm Motility Subpopulation Structure in Donkey and Horse
}

\author{
Sabrina Gacem ${ }^{1}$, Anthony Valverde ${ }^{2}$, Jaime Catalán ${ }^{1}$, Iván Yánez Ortiz ${ }^{1}$, Carles Soler ${ }^{3 *}$ \\ and Jordi Miró ${ }^{1 *}$ \\ 1 Equine Reproduction Service, Autonomous University of Barcelona, Department of Animal Medicine and Surgery Veterinary \\ Faculty, Catalonia, Spain, ${ }^{2}$ Costa Rica Institute of Technology, School of Agronomy, Alajuela, Costa Rica, ${ }^{3}$ Universitat de \\ València, Departamento de Biología Celular, Biología Funcional y Antropología Física, Burjassot, Valencia, Spain
}

\section{OPEN ACCESS}

Edited by:

Manuel Alvarez Rodriguez, Linköping University, Sweden

Reviewed by:

Abouzar Najafi,

University of Tehran, Iran

Cecilia Dall'Aglio,

University of Perugia, Italy

*Correspondence:

Carles Soler

carles.soler@uv.edu

Jordi Miró

jordi.miro@uab.cat

Specialty section:

This article was submitted to

Animal Reproduction -

Theriogenology,

a section of the journal

Frontiers in Veterinary Science

Received: 09 January 2021 Accepted: 07 April 2021

Published: 25 May 2021

Citation:

Gacem S, Valverde A, Catalán J, Yánez Ortiz I, Soler $C$ and Miró J (2021) A New Approach of Sperm Motility Subpopulation Structure in

Donkey and Horse.

Front. Vet. Sci. 8:651477. doi: 10.3389/fvets.2021.651477
This study aimed to characterize the sperm kinematic values with high frames per second, to define the subpopulation structure of a horse and a donkey and compare them. A total of 57 fresh semen ejaculates (26 Spanish and 16 Arabian horse breeds and 10 donkeys) were collected and subsequently analyzed for kinematic parameters using the Computer-aided sperm motility analysis ISAS ${ }^{\circledR}$ V1.2 system and using a Spermtrack ${ }^{\circledR}$ $10-\mu \mathrm{m}$ depth counting chamber. Sequences were recorded at 250 frames per second, and eight kinematic parameters were automatically evaluated. All kinematic parameters showed significant differences between a donkey and a horse and between horse breeds. All ejaculates evaluated showed excellent semen motility characteristics, with significantly higher values for all kinematic parameters for donkeys compared with horses except for beat-cross frequency. Donkey sperm was faster and linear than the horse. Regarding horse breeds differences, the Spanish horse had higher average path velocity, curvilinear velocity, and beat-cross frequency compared with the Arabian horse. Spanish horse sperm was rapid, but Arab horse was more linear. The principal component analysis showed three sperm subpopulations in the ejaculate of donkeys and horses with a significantly different motility characteristic between them. The dominant subpopulation for both donkey and horse was for rapid, straight, and linear with a high beat sperm (38.2 and $41.7 \%$, respectively), whereas the lowest subpopulation was for the slowest and non-linear sperms. This, plus slight differences in the distribution of these subpopulations between Arabian and Spanish horses, were found. In conclusion, higher frames permitted to have a new interpretation of motile subpopulations with species and breed differences. More so, future works on donkey and horse breed spermatozoa should take into account differences between breeds that may interfere and alter the real analysis performed.

Keywords: equids, sperm motility, subpopulations, sperm kinematics, CASA-mot

\section{INTRODUCTION}

All the present living species of equids are assigned to the genus Equus, sharing a common ancestor million years ago (1), being distributed worldwide in the most diverse environments. The Equus genus comprises two lineages: the caballine, which includes domesticated horses (Equus ferus caballus), and the wild endangered Przewalski's horse (Equus ferus przewalskii) of Mongolia, and 
non-caballine grouping, which comprises the asses and zebras (2). The domestication process for horses was initiated approximately 450 generations ago, assuming an average generation time of 12 years for wild horses, whereas that for donkeys was around 6,000 years ago (3).

The domestication process started with the need of humans to shape animals' species according to their intentions, producing an artificial selection pressure. The last one has increased particularly since the establishment of studbooks and the development of clear breading objectives affecting the fertility potential (4). Consequently, all the domestic species are now quite far from the original in different aspects involving reproductive characteristics.

The sperm analysis is a prerequisite for breeding soundness examination, and the use of semen in artificial insemination in horses is like in all farm animals. The introduction of computer-assisted semen analysis (CASA) technology allowed for an unprecedented degree of sophistication in the study of sperm characteristics and particularly in reference to kinematics patterns $(5,6)$. Computer-aided sperm motility analysis (CASAMot) systems capture sequences from microscopic fields and automatically analyze all sperm trajectories $(7,8)$, offering a battery of quantitative kinematic parameters (9).

Improvement in CASA technology and especially the development of new software solutions and new high-performing cameras permitted the authors to analyze better the sperm trajectory $(8,10-12)$. Recent studies have suggested specific optimum video capture frame rates for a mathematically welltrack definition in various species $(12,13)$. All the previous work using CASA-Mot systems was obtained using suboptimal kinematic data, which resulted in a low significance kinematic parameter. Those are some of the most important limitations in the general use of CASA technology in the past (5).

Furthermore, it was shown that spermatozoa could be grouped into coherent mathematical subpopulations in a wide variety of animals (14-16). These subpopulational structures were also observed for different morphological, biochemical, and physiological traits such as morphometry (17), DNA fragmentation (18), mitochondrial activity (19), osmotic properties (20), and functional status (21). What is clear nowadays is that the ejaculate is not composed of a homogeneous population of equivalent cells but a different subpopulation regarding various cellular properties. Its origin is related both to the testicular formation of the spermatozoa (22) and with their maturational process along the epididymis (23). Interestingly, it can be conditioned by external social interactions, almost in horses (24).

Our study aims to compare the distribution of these kinematic subpopulations between two close equid species horses and donkeys and two horse breeds Spanish and Arabian and that by using higher frames rate for sperm kinematic calculation.

\section{MATERIALS AND METHODS}

\section{Animals}

The study was conducted at the University Autonoma of Barcelona (Bellaterra, Cerdanyola del Vallès, Spain). Two ejaculates were collected from 13 pure Spanish breeds and eight pure Arabian horses, whereas three ejaculates were obtained from five Catalonian donkeys each, a total of 57 fresh ejaculates. Semen was collected from all animals three times a week throughout the year. All animals ranged from 3 to 15 years of age and fed three times a day with a standard diet (mixed hay and basic concentrate); water was also freely available. All the animals were housed in single boxes in the Equine Reproduction Service of the university. The housing facility is a European Union-approved semen collection center (authorization code: ES09RS01E) that operates under strict protocols of animal welfare and health control. All animals were semen donors and underwent regular semen collection under CEE health conditions (free of equine arteritis, infectious anemia, and contagious metritis). Because this service already runs under the approval of the Regional Government of Catalonia (Spain) and because no manipulation of the animals other than semen collection was carried out, the ethics committee of our institution indicated that no further ethical approval was required.

\section{Semen Collection}

Ejaculates were collected through a pre-warmed artificial vagina model Hannover (Minitüb GmbH, Tiefenbach, Germany) with animals excited by an ovariectomized mare or jenny. An in-line nylon mesh filter was used to separate the gel fraction from the semen. Upon collection, gel-free semen was diluted immediately $1: 5(\mathrm{v}: \mathrm{v})$ in skimmed milk (4.9\% glucose, $2.4 \%$ skim milk, and 100 -mL double-distilled water), previously preheated to $37^{\circ} \mathrm{C}$.

Sperm analysis (morphology and concentration) was evaluated upon arrival of semen samples to the laboratory. Sperm concentration was determined using a hemocytometer (Neubauer Chamber; Paul Marienfeld, Germany). To this end, samples were previously diluted with a $4 \%$ formalin buffered solution, and the sperm count was adjusted for the dilution factor. Sperm morphology was evaluated by the eosin-nigrosin staining technique.

\section{Semen Preparation and Computer-Assisted Semen Analysis}

The remaining sample was diluted to a final concentration of 40 $\times 10^{6}$ spermatozoa $/ \mathrm{mL}$, then a volume of $2 \mu \mathrm{L}$ was mounted on standardized 10- $\mu \mathrm{m}$ depth counting chambers Spermtrack ${ }^{\circledR}$ (Proiser R+D S.L., Paterna, Spain). All chambers were prewarmed and maintained at $37^{\circ} \mathrm{C}$ on a UB203 (Proiser $\mathrm{R}+\mathrm{D}$ )heated microscope stage throughout the analysis.

Sperm kinematic parameters were automatically assessed using the motility module of CASA system ISAS ${ }^{\circledR} \mathrm{v} 1$ (Integrated Sperm Analysis System V1.0; Proiser S.L.; Valencia, Spain). The device is a combination of a Proiser HS640m digital camera mounted on the referred microscope. Images were captured by a $10 \times$ negative phase contrast objective (AN 0.25). For each analysis, up to 10 non-consecutive fields were recorded for $3 \mathrm{~s}$ at 250 frames per second (fps) in each analysis, permitting the identification of a minimum of 500 spermatozoa per ejaculate.

The settings of the CASA system were those recommended by the manufacturer: particle area $>4$ and $<75 \mu \mathrm{m}^{2}$; connectivity: 6; cutoff values were VAP $\geq 10 \mu \mathrm{m} / \mathrm{s}$ for a sperm cell to be 
considered as motile $(10,11)$. The following sperm motility parameters were determined, sperm velocity: the curvilinear velocity (VCL), straight-line velocity (VSL), and average path velocity (VAP); and sperm movement trajectory: the frequency with which the actual track crossed the smoothed track in either direction [beat-cross frequency (BCF), hertz], and the maximum of the measured width of the head oscillation as the sperm cells swim (the amplitude of lateral head displacement [ALH]). Also, three progression proportions were calculated from the velocity measurements: (the linearity, LIN = VSL/ VCL), the departure of actual sperm track from linearity (wobble WOB $=\mathrm{VAP} / \mathrm{VCL}$ ), and linearity of the average path (straightness, STR = VSL/VAP).

\section{Statistical Analysis}

The data obtained from the analysis of all sperm variables were first tested for normality and homoscedasticity by using ShapiroWilks and Levene tests. A normal probability plot was used to check for a normal distribution. Multivariate procedures were performed to identify sperm subpopulations from the set of sperm motility data. All the values for kinematic variables were standardized to avoid any scaling effect.

\section{Multivariate Procedures Analysis}

Clustering procedures were performed to identify sperm subpopulations from the complete set of motility data. The first step was to perform a principal component analysis (PCA). The number of principal components (PCs) that should be used in the next step of the analysis was determined from the Kaiser criterion, namely selecting only those with an eigenvalue (variance extracted for that PC) $>1$. Furthermore, Bartlett's sphericity test and the Kaiser-Meyer-Olkin were performed. As a rotation method, the varimax method with Kaiser normalization was used. The second process was to perform a clustering procedure. A two-step cluster procedure was performed, a hierarchical and a non-hierarchical analysis model, with the sperm-derived indices obtained after the PCA, that uses Euclidean distances from the quantitative variables after standardization of these data, so the cluster centers were the means of the observations assigned to each cluster. In the first step, to determine the optimal number of clusters, the final centroids were clustered hierarchically using the Ward method (25). All sperm cells within different breeds and species were clustered by using the multivariate $\mathrm{k}$-means clustering procedure was made to classify the spermatozoa into a reduced number of subpopulations (clusters) according to their kinematic variables. The clustering procedure enables the identification of sperm subpopulations because each cluster contributed to a final cluster formed by the spermatozoa linked to the centroids. The analysis of variance and $\chi^{2}$-test procedures were applied to evaluate statistical differences in the distributions of observations (individual spermatozoa) within subpopulations, and then a generalized linear model procedure was used to determine the effects of the breed and species on the mean kinematic variable values defining the different sperm subpopulations (i.e., the cluster centers). Differences between means were analyzed by the Bonferroni test. Results are presented as mean \pm standard error of the mean (SEM). Statistical significance was considered at $P<$
0.05. All data were analyzed using the IBM SPSS package, version 23.0 for Windows (SPSS Inc., Chicago, IL, USA).

\section{RESULTS}

All the kinematic parameters showed significant differences between both species horse and donkey, being higher for donkey unless BCF was higher for the horse. This means that donkey sperm motility was more linear than that of a horse (Table 1).

When comparing Arabian and Spanish horses, VAP, VCL, ALH, and BCF were higher in Spanish horses than in Arabian, being the contrary for LIN and WOB. VSL, STR, and ALH showed no differences among breeds. Following these results, Spanish horse sperm was faster but less linear than an Arabian horse (Table 1).

The PCA rendered three PCs for both species, explaining $90.9 \%$ for stallion and $89.8 \%$ for the donkey of the total variance (Table 2). The three PCs were equivalent for donkey and stallion, being PC1, named velocity, positively correlated to the velocity parameters (VCL and VAP) and sperm head oscillation ALH for both species; only BCF was also included for a stallion. PC2, named linearity, was positively correlated to progressivity parameters (LIN and STR) and to VSL. Finally, PC3, named oscillation, was positively correlated to WOB in both species and negatively correlated also to BCF for donkey (Table 2).

These PCs were used to identify three well-defined subpopulations (SP1, SP2, and SP3) in both stallion and donkey, showing differences for all the kinematic parameters among them (Table 3, Figure 1). SP1 had the lowest value of all kinematic parameters, being named as the slow and non-linear subpopulation. SP2 included spermatozoa characterized by the highest linear trajectories (LIN and STR) and high speed (VCL, VSL, and VAP), ALH, and BCF. This subpopulation included the fast, straight, and lineal with a high tail beat spermatozoa subpopulation. SP3 was characterized by the highest VCL, VAP, $\mathrm{ALH}$, and BCF but low linear trajectories (LIN and STR), being defined as the fast with a high beat and non-linear subpopulation (Table 3).

The percentage of each subpopulation in reference to the total number of spermatozoa varied slightly between donkey and stallion. The stallion and donkey semen have the highest proportion of the fast, straight, and lineal with a high beat subpopulation (SP2: 38.2 and $41.7 \%$, respectively). SP3 was in the middle with $33.6 \%$ for stallion and $31.4 \%$ for donkey. In contrast, the lowest proportion was for the slow and non-linear subpopulation SP1 (28.2\% for stallion and $26.9 \%$ for donkey, Table 3).

The proportion of the three stallion subpopulations for Arabian and Spanish horse breeds was almost the same (Table 4).

\section{DISCUSSION}

Sperm competition plays an important role in sperm fertilization, so in male fertility and lead to a strong natural selection (26). Sperm competition occurs between sperm from two or more rival males making an attempt to fertilize a female within a sufficiently 
TABLE 1 | Sperm kinematic variables (mean \pm SEM) in horses and donkey.

\begin{tabular}{|c|c|c|c|c|}
\hline Variable/Breed & Arabian & Spanish & Total horse & Donkey \\
\hline VCL & $214.52 \pm 79.28^{a}$ & $232.45 \pm 89.55^{\mathrm{b}}$ & $224.96 \pm 85.87^{x}$ & $230.08 \pm 91.45^{y}$ \\
\hline VSL & $60.14 \pm 37.08^{a}$ & $59.21 \pm 34.83^{a}$ & $59.60 \pm 35.79^{x}$ & $78.07 \pm 48.01^{y}$ \\
\hline VAP & $161.59 \pm 66.0^{a}$ & $167.03 \pm 68.89^{b}$ & $164.76 \pm 67.75^{x}$ & $172.63 .73 \pm 63.08^{y}$ \\
\hline LIN & $26.99 \pm 11.95^{b}$ & $25.19 \pm 11.23^{a}$ & $25.94 \pm 11.57^{x}$ & $33.81 \pm 19.26^{y}$ \\
\hline STR & $36.36 \pm 15.50^{a}$ & $35.49 \pm 15.43^{a}$ & $35.85 \pm 15.46^{x}$ & $42.75 \pm 19.69^{y}$ \\
\hline WOB & $74.22 \pm 9.91^{b}$ & $71.21 \pm 9.13^{a}$ & $72.50 \pm 9.58^{x}$ & $74.89 \pm 14.08^{y}$ \\
\hline ALH & $1.18 \pm 0.26^{a}$ & $1.30 \pm 0.31^{b}$ & $1.25 \pm 0.30^{x}$ & $1.41 \pm 0.34^{y}$ \\
\hline $\mathrm{BCF}$ & $37.03 \pm 15.69^{a}$ & $39.25 \pm 14.92^{b}$ & $38.32 \pm 15.29^{y}$ & $33.99 \pm 18.78^{x}$ \\
\hline
\end{tabular}

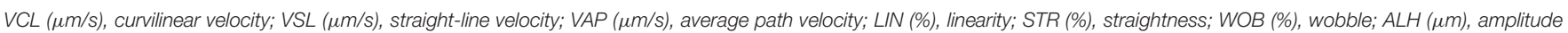

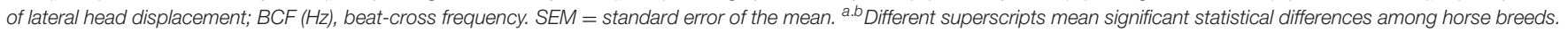
Different letters $(x, y)$ indicate differences among horse and donkey species $P<0.05$.

TABLE 2 | Eigenvectors of the three principal components obtained in the study of sperm kinematics for horse and donkey.

\begin{tabular}{|c|c|c|c|c|c|c|}
\hline & \multicolumn{3}{|c|}{ Horse } & \multicolumn{3}{|c|}{ Donkey } \\
\hline & PC1 & PC2 & PC3 & PC1 & PC2 & PC3 \\
\hline VCL & 0.96 & & & 0.86 & & \\
\hline VSL & & 0.79 & & & 0.82 & \\
\hline VAP & 0.90 & & & 0.93 & & \\
\hline LIN & & 0.97 & & & 0.89 & \\
\hline STR & & 0.98 & & & 0.98 & \\
\hline WOB & & & 0.97 & & & 0.90 \\
\hline ALH & 0.90 & & & 0.84 & & \\
\hline BCF & 0.73 & & & & & -0.67 \\
\hline Explained variation (\%) & 42.47 & 32.48 & 15.96 & 36.92 & 32.51 & 20.40 \\
\hline
\end{tabular}

PC1, principal component designated "velocity;" PC2, principal component designated "linearity;" PC3, principal component designated "oscillation." VCL $(\mu \mathrm{m} / \mathrm{s})$, curvilinear velocity; VSL $(\mu \mathrm{m} / \mathrm{s})$, straight line velocity; $\operatorname{VAP}(\mu \mathrm{m} / \mathrm{s})$, average path velocity; LIN (\%), linearity; STR (\%), straightness; WOB (\%), wobble; ALH ( $\mu \mathrm{m})$, amplitude of lateral head displacement; $B C F(\mathrm{~Hz})$, beat-cross frequency. Only eigenvectors $>0.6$ are presented for each principal component.

short period (27). This fact has been evidenced not only in mammalian but also in bird (28), fish (29), reptile (30), and insect (31) species. This relevance affects the sperm morphology leading to a production of longer sperms with larger mid-piece (32) and also affecting the head morphometry among close related camelids species (33).

The action of humans along domestication practice implied that natural selection had been replaced by strong artificial selection $(34,35)$. Domestication of equids took place in the Bronze Age for both horses (36) and donkeys (37). Artificial insemination practice meant a considerable advance in reproduction, and consequently in artificial selection, in all farm animals $(38,39)$ and recently started in donkey (40). The results presented here showed how close stallion and donkey species are, almost regarding sperm kinematics. In fact, there are more differences between the two considered stallion breeds than between one of them and the donkey. In some mammalian species, like camelids (33), offspring obtained by crossing different species remains fertile, but this is not the case in equids being expected to find higher differences in sperm kinematics. Effectively, the reproductive isolating mechanism is one of the most important speciation processes, and it is frequently related to sperm characteristics variation (41). In equid, species remain very close genetically, being able to produce hybrids viable but not fertile. So, a hinny is a domestic equine hybrid that is the offspring of a male horse (a stallion) and a female donkey (a jenny). It is the reciprocal cross to the more common mule, which is the product of a male donkey (a jack) and a female horse (a mare). Even more, both species can have hybrid offspring with zebras, indicating that evolutive divergency among this species is not enough to avoid reproduction among them.

From the methodological point of view, the results showed in the present work were obtained using the optimal frame rate for both species and stallion breeds $(10,11)$. Therefore, the subsequent subpopulation analyzed can be considered of high confidence.

Horse and donkey spermatozoa have a different way to move, as the donkey sperm is faster with a more linear trajectory compared with the horse. These differences were also appreciable at a frame rate of $25 \mathrm{fps}$ (42).

To the best of our knowledge, only a few studies compared different horse breeds motility parameters and semen quality (43). Unfortunately, most of those works did not take into consideration kinematic variation between breeds. In the present study, we observed that Spanish breeds present higher sperm velocities (VCL and VAP) than Arab breeds, who showed higher linearity and sperm oscillation.

To complete the classical studies based on the comparison of the median values of each parameter as independent variables, the multivariate statistical procedures, including a reduction of dimensionality by PCA followed by clustering analysis, were developed to define sperm subpopulations (44, 45). During the last years, several studies have shown the universal presence of defined subpopulation structure inside the whole sperm population in the ejaculate (20,46-48). This fact has changed the previously established paradigm that considered the ejaculate composed of "equivalent" cells 
TABLE 3 | Descriptive statistics for the CASA-Mot variables (mean \pm SD) for each sperm subpopulation species, horse, and donkey samples.

\begin{tabular}{|c|c|c|c|c|c|c|}
\hline & \multicolumn{3}{|c|}{ Horse } & \multicolumn{3}{|c|}{ Donkey } \\
\hline & SP1 & SP 2 & SP 3 & SP 1 & SP 2 & SP 3 \\
\hline$n$ & 5,606 & 7,626 & 6,714 & 4,851 & 7,549 & 5,678 \\
\hline$\%$ sperms & 28.1 & 38.2 & 33.6 & 26.8 & 41.7 & 31.4 \\
\hline VCL & $134.6 \pm 48.17^{a}$ & $233.45 \pm 59.08^{b}$ & $290.77 \pm 69.08^{c}$ & $142.33 \pm 47.41^{a}$ & $245.8 \pm 75.51^{b}$ & $286.73 \pm 83.72^{\mathrm{C}}$ \\
\hline VSL & $26.29 \pm 15.67^{a}$ & $85.59 \pm 30.66^{c}$ & $57.89 \pm 28.88^{b}$ & $26.18 \pm 17.15^{a}$ & $116.42 \pm 32.80^{c}$ & $71.41 \pm 36.83^{b}$ \\
\hline VAP & $86.18 \pm 30.08^{a}$ & $176.51 \pm 46.0^{b}$ & $217.01 \pm 49.33^{c}$ & $92.65 \pm 29.88^{a}$ & $191.89 \pm 39.25^{b}$ & $215.36 \pm 45.55^{c}$ \\
\hline LIN & $18.91 \pm 8.14^{a}$ & $36.6 \pm 7.97^{c}$ & $19.7 \pm 7.80^{\mathrm{b}}$ & $18.35 \pm 10.73^{a}$ & $50.29 \pm 15.50^{c}$ & $25.1 \pm 11.01^{b}$ \\
\hline STR & $29.7 \pm 13.48^{b}$ & $48.63 \pm 10.86^{c}$ & $26.48 \pm 10.94^{a}$ & $27.19 \pm 14.18^{a}$ & $60.67 \pm 10.58^{c}$ & $32.21 \pm 12.96^{b}$ \\
\hline WOB & $64.67 \pm 10.08^{a}$ & $75.87 \pm 7.47^{\mathrm{c}}$ & $75.21 \pm 7.16^{b}$ & $66.04 \pm 14.83^{a}$ & $79.21 \pm 14.11^{\mathrm{C}}$ & $76.69 \pm 13.26^{b}$ \\
\hline ALH & $1.03 \pm 0.23^{a}$ & $1.23 \pm 0.22^{b}$ & $1.46 \pm 0.27^{\mathrm{c}}$ & $1.08 \pm 0.21^{a}$ & $1.46 \pm 0.25^{b}$ & $1.63 \pm 0.29^{c}$ \\
\hline BCF & $22.64 \pm 10.89^{a}$ & $41.85 \pm 13.11^{b}$ & $47.41 \pm 9.88^{c}$ & $22.07 \pm 11.66^{a}$ & $36.8 \pm 19.98^{b}$ & $40.43 \pm 17.39^{c}$ \\
\hline
\end{tabular}

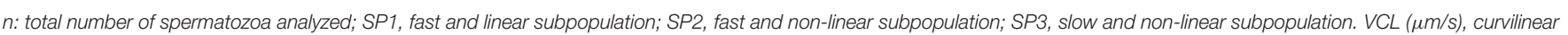

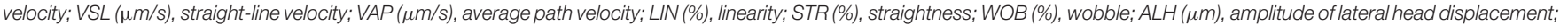

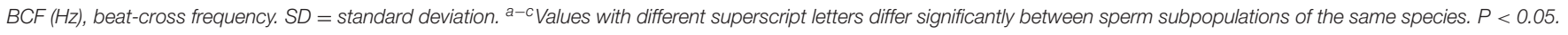

competing for reaching the oocyte fertilization. Effectively, some kind of synergies must be present among sperm subpopulations for achieving the final goal of successful fertilization $(6,49)$.

In the present study, the whole collection of kinematic data was grouped into three PCs in donkey ejaculate, named velocity, progressiveness, and cell oscillation. Using this twostep approach, three subpopulations were obtained, showing that the most frequent SP was for the fastest with high linearity ( $42 \%$ of the total). In a previous study conducted on the Andalusian donkey, four subpopulations were observed, with the main subpopulation (36\%) corresponding to low-velocity and high progressive spermatozoa and only $30 \%$ corresponding to progressive with high-velocity subpopulation (50). However, it is important to consider that the authors used a CASA-Mot system with only $25 \mathrm{fps}$, and the statistical procedure was a simple step clustering analysis.

Regarding the horse, the patter bot, both PCs and subpopulations were very similar to that observed in donkey, even if there were significant differences in the kinematic parameters between both species. Again, previous work showed four subpopulations but using a frame rate of just $16 \mathrm{fps}$ (48). Even more, up to six subpopulations were found in other work using a frame rate of $25 \mathrm{fps}$ and following a one-step statistical analysis (46).

All these differences can show the frame rate importance in a correct interpretation of sperm trajectories and the errors that can occur with fewer frames. These changes in sperm trajectories found between different frames also change the real distribution of sperm subpopulations of an ejaculate, all resulting in a misunderstanding of the real role of each subpopulation and its capacity to arrive at the oocyte and fertilize it.

Finally, in reference to the horse breeds considered here, there were no important differences in the sperm subpopulation structure, being little differences in the presence of some of the subpopulations. Instead of this, VCL and VAP for all subpopulations showed significant differences with higher velocities for the Spanish breed compared with Arabian. This could be explained by the history of the domestication of horses who spread out of western central Eurasia, place of origin, that started combined with the continued high genetic input from local wild populations; this hybridization increased genetic differentiation in population, which were accentuated by the human force that shaped their need for creating highly competing horses (1). This hybridization has affected the shape and the performance of the spermatozoa in different degrees depending on the breed, resulting in a decrease in per-cycle conception rates, at around $60 \%$ than those observed for other domestic livestock species (51). The Arabian horse is considered one of the most ancestral, with pure pedigree even if it was shown with the recent study of mitochondrial DNA sequences that there is heterogenicity and great diversity among this breed (52), whereas the pure Spanish horse is considered the first European "warmblood," a mixture of heavy European and lighter Oriental horses, taking its origin from the Andalusia Spanish region that is recognized as a distinct breed since the 15th century (53). Similar differences have been observed in other species like a bull (54), boar (55), and dog (56), showing how much artificial selection procedures conduces to processes close to the speciation process in natural selection (33).

In conclusion, a new performing camera permitted to acquire higher frames for better sperm motility analysis and therefore get more reliable results approachable to real sperm move and changing the old perspectives. The sperm had significantly higher values for all kinematic parameters for the donkey than the horse. Donkey sperm was faster and linear than the horse. Regarding horse breed differences, Spanish horse sperm is rapid, but Arab horse is more linear. The cluster analysis showed three sperm subpopulations; the predominant motile subpopulation in freshly ejaculated horse and donkey sperm had very fast velocity characteristics and a linear trajectory with a high beat frequency. Finally, the 


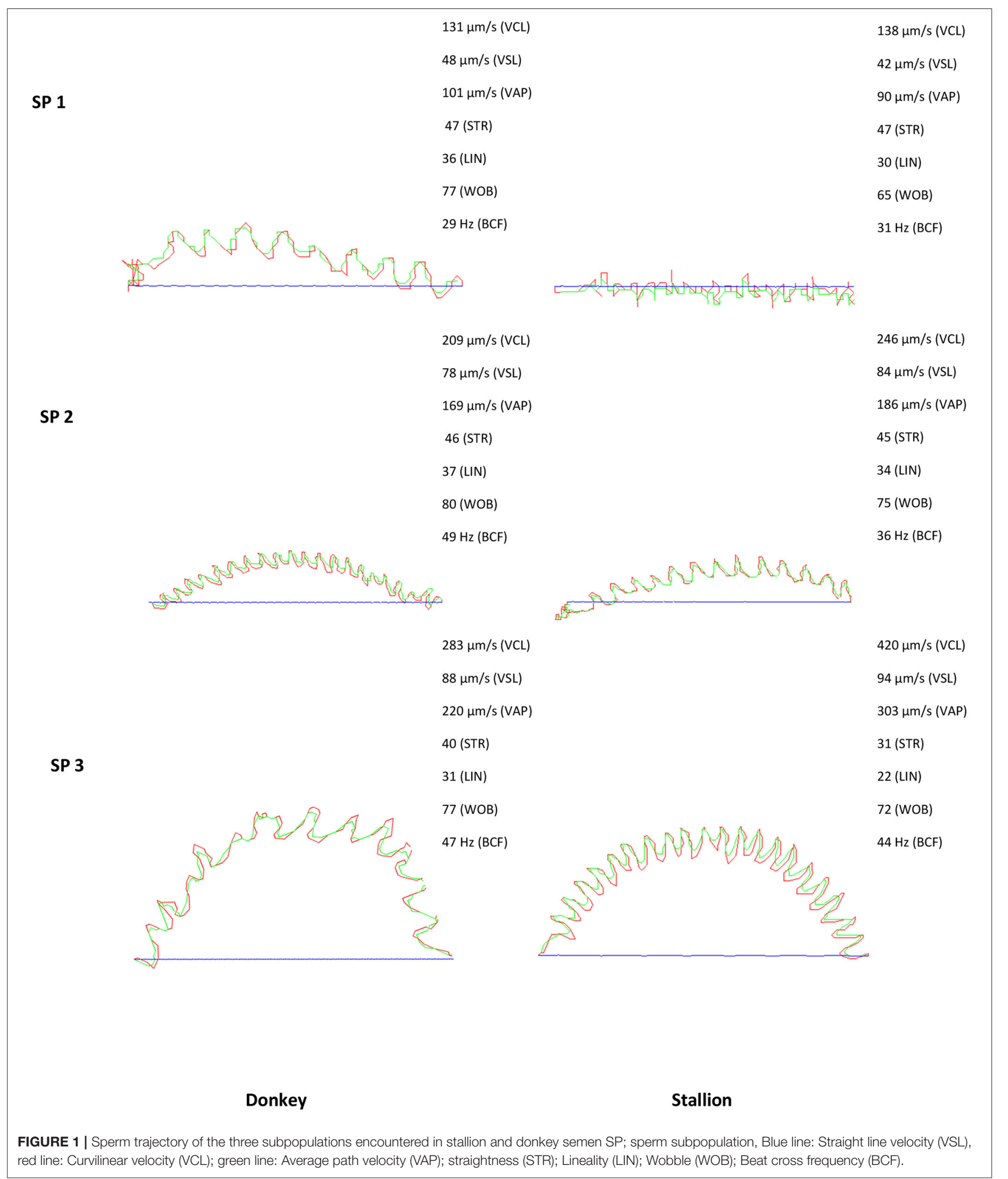

identification and differentiation of the structure of functional sperm subpopulations seem to be an advantageous key element as a valuable alternative tool to successfully detect and improve critical handling of further treatment where the effect of the breed would be considered to avoid alterations in the interpretations of the analysis. 
TABLE 4 | Descriptive statistics for the CASA-Mot variables (mean \pm SEM) for each sperm subpopulation in two horse breeds, Arabian and Spanish.

\begin{tabular}{|c|c|c|c|c|c|c|}
\hline & \multicolumn{3}{|c|}{ Arabian } & \multicolumn{3}{|c|}{ Spanish } \\
\hline & SP1 & SP 2 & SP 3 & SP 1 & SP 2 & SP 3 \\
\hline$n$ & 2,831 & 3,366 & 2,128 & 3,942 & 4,917 & 2,762 \\
\hline$\%$ sperms & $34 \%$ & $40 \%$ & $26 \%$ & $34 \%$ & $42 \%$ & $24 \%$ \\
\hline VCL & $136.10 \pm 47.84^{a}$ & $263.81 \pm 59.32^{\mathrm{c}}$ & $240.88 \pm 57.11^{b}$ & $142.41 \pm 45.87^{a}$ & $295.39 \pm 69.05^{c}$ & $248.89 \pm 57.97^{b}$ \\
\hline VSL & $30.05 \pm 17.47^{a}$ & $61.34 \pm 26.72^{b}$ & $98.25 \pm 34.41^{c}$ & $31.51 \pm 17.57^{\mathrm{a}}$ & $61.69 \pm 29.51^{b}$ & $94.35 \pm 27.80^{c}$ \\
\hline VAP & $90.61 \pm 32.52^{a}$ & $206.71 \pm 44.26^{c}$ & $184.63 \pm 45.64^{b}$ & $93.47 \pm 31.18^{a}$ & $219.44 \pm 48.70^{c}$ & $178.69 \pm 40.09^{b}$ \\
\hline LIN & $21.30 \pm 9.45^{a}$ & $23.04 \pm 8.10^{b}$ & $40.79 \pm 8.82^{c}$ & $21.28 \pm 8.91^{a}$ & $20.99 \pm 8.66^{a}$ & $38.25 \pm 7.76^{b}$ \\
\hline STR & $32.11 \pm 14.28^{b}$ & $29.25 \pm 10.12^{a}$ & $53.24 \pm 10.85^{c}$ & $32.38 \pm 13.34^{b}$ & $28.14 \pm 11.53^{a}$ & $53.02 \pm 9.68^{c}$ \\
\hline WOB & $66.86 \pm 10.12^{a}$ & $78.90 \pm 6.82^{\mathrm{c}}$ & $76.89 \pm 7.77^{b}$ & $65.86 \pm 10.01^{a}$ & $74.82 \pm 6.65^{\mathrm{c}}$ & $72.42 \pm 7.95^{b}$ \\
\hline ALH & $1.02 \pm 0.22^{a}$ & $1.31 \pm 0.23^{c}$ & $1.19 \pm 0.23^{b}$ & $1.05 \pm 0.21^{b}$ & $1.47 \pm 0.28^{c}$ & $0.34 \pm 0.25^{a}$ \\
\hline $\mathrm{BCF}$ & $23.84 \pm 11.91^{a}$ & $45.33 \pm 11.11^{\mathrm{c}}$ & $41.46 \pm 14.81^{b}$ & $25.77 \pm 11.94^{a}$ & $47.39 \pm 9.78^{c}$ & $44.00 \pm 12.79^{b}$ \\
\hline
\end{tabular}

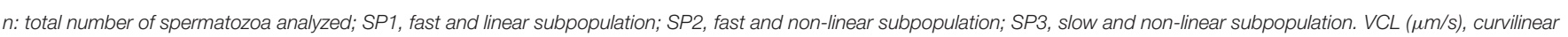

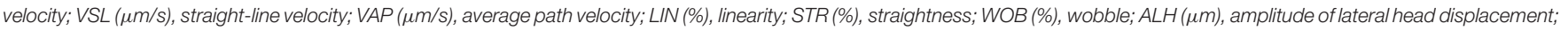

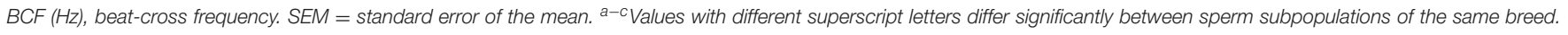
$P<0.05$.

Future work is needed to define the relationship of the observed sperm subpopulation structures and the fertility of the samples, considering the effect of different breeds.

\section{DATA AVAILABILITY STATEMENT}

The raw data supporting the conclusions of this article will be made available by the authors, without undue reservation.

\section{ETHICS STATEMENT}

Ethical review and approval was not required for the animal study because the ethics committee considered no necessary as explained in the text.

\section{AUTHOR CONTRIBUTIONS}

CS and JM: conceptualization, validation, visualization, and supervision. SG, JC, IY, and JM: methodology. CS: software. AV:

\section{REFERENCES}

1. Orlando L, Ginolhac A, Zhang G, Froese D, Albrechtsen A, Stiller M, et al. Recalibrating equus evolution using the genome sequence of an early Middle Pleistocene horse. Nature. (2013) 499:74-8. doi: 10.1038/nature12323

2. Zeder MA, Bradley DG, Emshwiller E, Smith BD. Documenting Domestication: New Genetic and Archaeological Paradigms. Oakland, CA: University of California Press (2006). doi: 10.1525/9780520932425

3. Clutton-Brock J. Horse Power: A History of the Horse and the Donkey in Human Societies. Cambridge, MA: Harvard University Press (1992).

4. Thornton PK. Livestock production: recent trends, future prospects. Philos Trans R Soc B Biol Sci. (2010) 365:2853-67. doi: 10.1098/rstb.2010.0134

5. Amann RP, Waberski D. Computer-assisted sperm analysis (CASA): capabilities and potential developments. Theriogenology. (2014) 81:5-17. doi: 10.1016/j.theriogenology.2013.09.004

6. Valverde A, Castro-morales O, Madrigal-valverde M, Soler C. Sperm kinematics and morphometric subpopulations analysis with CASA systems : a review. Rev Biol Trop. (2019) 67:1473-87. doi: 10.15517/rbt.v67i6.35151 formal analysis. SG, JC, and JM: investigation. SG and CS: data curation. SG and AV: writing_-original draft preparation. SG, CS, and JM: writing - review and editing. All authors have read and agreed to the published version of the manuscript.

\section{FUNDING}

This work was funded by the Equine Reproduction Service, Department of Animal Medicine and Surgery, Faculty of Veterinary Medicine, Autonomous University of Barcelona, Spain. JC was funded by the National Agency for Research and Development (ANID), Ministry of Education, Chile (Scheme: Becas Chile Doctorado en el Extranjero, PFCHA; Grant: 2017/72180128). IY was funded by Secretary of Higher Education, Science, Technology and Innovation (SENESCYT), Ecuador (Scheme: Programa de Becas Internacionales de Posgrado 2019; Grant: CZ02-000507-2019).

7. Gallagher MT, Smith DJ, Kirkman-Brown JC. CASA: tracking the past and plotting the future. Reprod Fertil Dev. (2018) 30:867. doi: 10.1071/RD 17420

8. Gallagher MT, Cupples G, Ooi EH, Kirkman-Brown JC, Smith DJ. Rapid sperm capture: high-throughput flagellar waveform analysis. Hum Reprod. (2019) 34:1173-85. doi: 10.1101/551267

9. Soler C, Valverde A, Bompart D, Fereidounfar S, Sancho M, Yániz J, et al. New methods of semen analysis by casa. Agric Biol. (2017) 52:232-41. doi: 10.15389/agrobiology.2017.2.232eng

10. Gacem S, Bompart D, Valverde A, Catalán J, Miró J, Soler C. Optimal frame rate when there were stallion sperm motility evaluations and determinations for kinematic variables using CASA-Mot analysis in different counting chambers. Anim Reprod Sci. (2020) 223:10664. doi: 10.1016/j.anireprosci.2020.106643

11. Gacem S, Catalán J, Valverde A, Soler C, Miró J. Optimization of Casamot analysis of donkey sperm: optimum frame rate and values of kinematic variables for different counting chamber and fields. Animals. (2020) 10:1-16. doi: 10.3390/ani10111993 
12. Bompart D, García-Molina A, Valverde A, Caldeira C, Yániz J, Núñez De Murga M, et al. CASA-Mot technology: how results are affected by the frame rate and counting chamber. Reprod Fertil Dev. (2018) 30:810-9. doi: $10.1071 /$ RD17551

13. Valverde A, Madrigal M, Caldeira C, Bompart D, de Murga JN, Arnau S, et al. Effect of frame rate capture frequency on sperm kinematic parameters and subpopulation structure definition in boars, analysed with a CASA-Mot system. Reprod Domest Anim. (2019) 54:167-75. doi: 10.1111/rda.13320

14. Yániz J, Vicente-Fiel S, Soler C, Recreo P, Carretero T, Bono A, et al. Comparison of different statistical approaches to evaluate morphometric sperm subpopulations in man. Asian J Androl. (2016) 18:819-23. doi: 10.4103/1008-682X.186872

15. Abaigar T, Holt W, Harrison R, del Barrio G. Sperm subpopulations in boar (Sus scrofa) and gazelle (Gazella dama mhorr) semen as revealed by pattern analysis of computer-assisted motility assessments. Biol Reprod. (1999) 60:32-41. doi: 10.1095/biolreprod60.1.32

16. García-Molina A, Valverde A, Bompart D, Caldeira C, Vendrell A, Soler C. Updating semen analysis: a subpopulation approach. Asian J Androl. (2019) 22:118-9. doi: 10.4103/aja.aja_33_19

17. Yániz JL, Soler C, Santolaria P. Computer assisted sperm morphometry in mammals: a review. Anim Reprod Sci. (2015) 156:1-12. doi: 10.1016/j.anireprosci.2015.03.002

18. Urbano M, Ortiz I, Dorado J, Hidalgo M. Identification of sperm morphometric subpopulations in cooled-stored canine sperm and its relation with sperm DNA integrity. Reprod Domest Anim. (2017) 52:468-76. doi: 10.1111/rda.12935

19. Sousa AP, Amaral A, Baptista M, Tavares R, Caballero Campo P, Caballero Peregrín P, et al. Not all sperm are equal: functional mitochondria characterize a subpopulation of human sperm with better fertilization potential. PLoS ONE. (2011) 6:e18112. doi: 10.1371/journal.pone.0018112

20. Oldenhof $\mathrm{H}$, Blässe $\mathrm{AK}$, Wolkers WF, Bollwein H, Sieme H. Osmotic properties of stallion sperm subpopulations determined by simultaneous assessment of cell volume and viability. Theriogenology. (2011) 76:386-91. doi: 10.1016/j.theriogenology.2011.02.027

21. Pérez-Llano B, Yenes-García P, García-Casado P. Four subpopulations of boar spermatozoa defined according to their response to the short hypoosmotic swelling test and acrosome status during incubation at $37^{\circ} \mathrm{C}$. Theriogenology. (2003) 60:1401-7. doi: 10.1016/S0093-691X(03)00131-6

22. Borowsky R, Luk A, He X, Kim RS. Unique sperm haplotypes are associated with phenotypically different sperm subpopulations in Astyanax fish. BMC Biol. (2018) 16:72. doi: 10.1186/s12915-018-0538-z

23. Gutiérrez-Reinoso M, García-Herreros M. Normozoospermic versus teratozoospermic domestic cats: Differential testicular volume, sperm morphometry, and subpopulation structure during epididymal maturation. Asian J Androl. (2016) 18:871-8. doi: 10.4103/1008-682X.187583

24. Burger D, Dolivo G, Wedekind C. Ejaculate characteristics depend on social environment in the horse (Equus caballus). PLoS ONE. (2015) 10:e0143185. doi: 10.1371/journal.pone.0143185

25. Murtagh F, Legendre P. Ward's Hierarchical Agglomerative Clustering Method: Which Algorithms Implement Ward's Criterion? J Classif. (2014) 31:274-95. doi: 10.1007/s00357-014-9161-z

26. Tourmente M, Varea-Sánchez M, Roldan ERS. Faster and more efficient swimming: energy consumption of murine spermatozoa under sperm competition. Biol Reprod. (2019) 100:420-8. doi: 10.1093/biolre/ioy197

27. Tourmente M, Gomendio M, Roldan ER. Sperm competition and the evolution of sperm design in mammals. Anim Reprod Sci. (2011) 156:1-12. doi: 10.1186/1471-2148-11-12

28. Dunn PO, Whittingham LA, Pitcher TE. Mating systems, sperm competition, and the evolution of sexual dimorphism in birds. Evolution. (2001) 55:161-75. doi: 10.1111/j.0014-3820.2001.tb01281.x

29. Stoltz JA, Neff BD. Sperm competition in a fish with external fertilization: the contribution of sperm number, speed and length. J Evol Biol. (2006) 19:1873-81. doi: 10.1111/j.1420-9101.2006.01165.x

30. Friesen CR, Kahrl AF, Olsson M. Sperm competition in squamate reptiles. Philos Trans R Soc B Biol Sci. (2020) 375:20200079. doi: 10.1098/rstb.2020.0079

31. García-González F, Simmons LW. Sperm viability matters in insect sperm competition. Curr Biol. (2005) 15:271-5. doi: 10.1016/j.cub.2005. 01.032
32. Firman RC, Simmons LW. Sperm midpiece length predicts sperm swimming velocity in house mice. Biol Lett. (2010) 6:513-6. doi: 10.1098/rsbl.2009.1027

33. Soler C, Sancho M, García A, Fuentes MC, Núñez J, Cucho H. Ejaculate fractioning effect on llama sperm head morphometry as assessed by the ISAS ${ }^{\circledR}$ CASA system. Reprod Domest Anim. (2014) 49:71-8. doi: $10.1111 /$ rda.12226

34. Kowalczyk A, Czerniawska-Piatkowska E, Kuczaj M. Factors influencing the popularity of artificial insemination of Mares in Europe. Animals. (2019) 9:460. doi: 10.3390/ani9070460

35. Morrell JM. Artificial insemination: current and future trends. In: Artificial Insemination in Farm Animals. London: InTech (2011).

36. Guimaraes S, Arbuckle BS, Peters J, Adcock SE, Buitenhuis H, Chazin H, et al. Ancient DNA shows domestic horses were introduced in the southern caucasus and anatolia during the bronze age. Sci Adv. (2020) 6:eabb0030. doi: 10.1126/sciadv.abb0030

37. Greenfield HJ, Shai I, Greenfield TL, Arnold ER, Brown A, Eliyahu A, et al. Earliest evidence for equid bit wear in the ancient Near East: The "ass" from Early Bronze Age Tell eș-Sâfi/Gath, Israel. PLoS ONE. (2018) 13:e0196335. doi: 10.1371/journal.pone.0196335

38. Allen WR. The development and application of the modern reproductive technologies to horse breeding. Reprod Domest Anim. (2005) 40:310-29. doi: 10.1111/j.1439-0531.2005.00602.x

39. Samper JC, Plough T. Techniques for the insemination of low doses of stallion sperm. Reprod Domest Anim. (2010) 45:35-9. doi: 10.1111/j.1439-0531.2010.01632.x

40. Canisso IF, Panzani D, Miró J, Ellerbrock RE. Key aspects of donkey and mule reproduction. Vet Clin North Am - Equine Pract. (2019) 35:607-42. doi: 10.1016/j.cveq.2019.08.014

41. Howard DJ, Palumbi SR, Birge LM, Manier MK. Sperm and speciation. Sperm Biol. (2009) 367-403. doi: 10.1016/B978-0-12-372568-4.00009-4

42. Miró J, Lobo V, Quintero-Moreno A, Medrano A, Peña A, Rigau T. Sperm motility patterns and metabolism in Catalonian donkey semen. Theriogenology. (2005) 63:1706-16. doi: 10.1016/j.theriogenology.2004.07.022

43. Gottschalk M, Sieme H, Martinsson G, Distl O. Analysis of breed effects on semen traits in light horse, warmblood, and draught horse breeds. Theriogenology. (2016) 85:1375-81. doi: 10.1016/j.theriogenology.2015.11.030

44. Ibanescu I, Siuda M, Bollwein H. Motile sperm subpopulations in bull semen using different clustering approaches - associations with flow cytometric sperm characteristics and fertility. Anim Reprod Sci. (2020) 215:106329. doi: 10.1016/j.anireprosci.2020.106329

45. Ramón M, Martínez-Pastor F. Implementation of novel statistical procedures and other advanced approaches to improve analysis of CASA data. Reprod Fertil Dev. (2018) 30:860. doi: 10.1071/RD17479

46. Ortega-Ferrusola C, Macías García B, Suárez Rama V, Gallardo-Bolaños J, González-Fernández L, Tapia J, et al. Identification of sperm subpopulations in stallion ejaculates: changes after cryopreservation and comparison with traditional statistics. Reprod Domest Anim. (2009) 44:419-23. doi: 10.1111/j.1439-0531.2008.01097.x

47. Ortiz I, Dorado J, Morrell JM, Diaz-Jimenez MA, Pereira B, Consuegra $\mathrm{C}$, et al. Comparison of sperm selection techniques in donkeys: motile subpopulations from a practical point of view. Anim Reprod. (2019) 16:282-9. doi: 10.21451/1984-3143-AR2018-0133

48. Quintero-Moreno A, Miró J, Teresa Rigau A, Rodríguez-Gil JE. Identification of sperm subpopulations with specific motility characteristics in stallion ejaculates. Theriogenology. (2003) 59:1973-90. doi: 10.1016/S0093-691X(02)01297-9

49. Víquez L, Barquero V, Soler C, Roldan ERS, Valverde A. Kinematic subpopulations in bull spermatozoa: A comparison of classical and bayesian approaches. Biology. (2020) 9:1-16. doi: 10.3390/biology9060138

50. Dorado J, Acha D, Gálvez MJ, Ortiz I, Carrasco JJ, Díaz B, et al. Sperm motility patterns in Andalusian donkey (Equus asinus) semen: effects of body weight, age, and semen quality. Theriogenology. (2013) 79:1100-9. doi: 10.1016/j.theriogenology.2013.02.006

51. Nath L, Anderson G, McKinnon A. Reproductive efficiency of thoroughbred and Standardbred horses in north-east Victoria. Aust Vet J. (2010) 88:169-75. doi: 10.1111/j.1751-0813.2010.00565.x

52. Głazewska I. Speculations on the origin of the Arabian horse breed. Livest Sci. (2010) 129:49-55. doi: 10.1016/j.livsci.2009.12.009 
53. Royo LJ, Álvarez I, Beja-Pereira A, Molina A, Fernández I, Jordana J, et al. The origins of iberian horses assessed via mitochondrial DNA. J Hered. (2005) 96:663-9. doi: 10.1093/jhered/esi116

54. Valverde A, Areán H, Fernández A, Bompart D, García-Molina A, LópezViana J, et al. Combined effect of type and capture area of counting chamber and diluent on Holstein bull sperm kinematics. Andrologia. (2018) 51:1-10. doi: $10.1111 /$ and.13223

55. Waterhouse KE, Hofmo PO, Tverdal A, Jr RRM. Within and between breed differences in freezing tolerance and plasma membrane fatty acid composition of boar sperm. Reproduction. (2006) 131:887-94. doi: 10.1530/rep.1. 01049

56. Valverde A, Arnau S, García-Molina A, Bompart D, Campos M, Roldán E, et al. Dog sperm swimming parameters analysed by computer-assisted semen analysis of motility reveal major breed differences. Reprod Domest Anim. (2019) 54:795-803. doi: 10.1111/rda. 13420

Conflict of Interest: The authors declare that the research was conducted in the absence of any commercial or financial relationships that could be construed as a potential conflict of interest.

Copyright $\odot 2021$ Gacem, Valverde, Catalán, Yánez Ortiz, Soler and Miró. This is an open-access article distributed under the terms of the Creative Commons Attribution License (CC BY). The use, distribution or reproduction in other forums is permitted, provided the original author(s) and the copyright owner(s) are credited and that the original publication in this journal is cited, in accordance with accepted academic practice. No use, distribution or reproduction is permitted which does not comply with these terms. 